HORTSCIENCE 25(11):1431-1434. 1990.

\title{
Isozyme Verification of Interspecific Hybrids of Cuphea
}

\author{
Daniel H. Ronis ${ }^{1}$, Anson E. Thompson', David A. Dierig ${ }^{1}$, and \\ Earl R. Johnson ${ }^{2}$ \\ U.S. Water Conservation Laboratory, Agricultural Research Service, \\ U.S. Department of Agriculture, Phoenix, AZ 85040
}

Additional index words. banding patterns

\begin{abstract}
Five interspecific Cuphea hybrids were examined for isozyme banding patterns. In three of the five hybrids $(C$. viscosissima $\times C$. lutea, $C$. ignea $\times C$. angustifolia, and $C$. lanceolata $\times C$. viscosissima), $F_{1}$ plants could be distinguished from either parental species. Phosphoglucomutase and 6-phosphogluconic dehydrogenase enzyme stains produced distinct $F_{1}$ band patterns for all three hybrids. Phosphoglucose isomerase and shikimate dehydrogenase enzyme stains produced distinct $F_{1}$ band patterns for $C$. viscosissima $\times C$. lutea and $C$. lanceolata $\times C$. viscosissima, respectively. For the $C$. lanceolata $\times C$. viscosissima hybrid. the banding patterns were used to identify 32 selfs among 161 putative $F_{1}$ plants.
\end{abstract}

Efforts are underway to domesticate various species of the genus Cuphea as new sources of medium-chain fatty acids and as new floral and bedding plants (Hirsinger, 1985; Hirsinger and Knowles, 1984; Thompson, 1984, 1985; Thompson and Kleiman, 1988; Thompson et al., 1987). The USDA-ARS program in cooperation with the

Received for publication 13 Mar. 1989. Mention of a trademark or proprietary product does not constitute a guarantee or warranty of the product by the U.S. Dept. of Agriculture nor does it imply approval to the exclusion of other products that may be similar. The cost of publishing this paper was defrayed in part by the payment of page charges. Under postal regulations, this paper therefore must be hereby marked advertisement solely to indicate this fact.

${ }^{1}$ Research Plant Geneticist.

${ }^{2}$ Research Technician.
Univ. of Arizona has concentrated its $\mathrm{Cu}$ phea breeding efforts on interspecific hybridization as a means of combining favorable traits found in various species. Successful interspecific hybrids have been obtained among several Cuphea species (Gathman and Ray, 1987; Ray et al., 1988, 1989). Two of these interspecific hybrids, C. viscosissima $(\mathrm{N}=6) \times C$. lutea $(\mathrm{N}=14)$ and $C$. ignea $(\mathrm{N}=16) \times C$. angustifolia $(\mathrm{N}=12)$, are sterile, probably due to chromosome pairing difficulties, particularly in these cases, where the parents have unequal chromosome numbers. However, the hybrid C. llavea $(\mathrm{N}=$ $9) \times C$. procumbens $(\mathrm{N}=9)$ and its reciprocal are fertile (Ray et al., 1988, 1989). The $\mathrm{F}_{1}$ of a previously unreported interspecific hybrid involving $C$. lanceolata $(\mathrm{N}=6)$ and C. viscosissima $(\mathrm{N}=6)$ has also proved to be fertile and has produced abundant $\mathrm{F}_{2}$ seed. Another interspecific hybrid, C. leptopoda 
Table 1. Utility of several enzyme systems for distinguishing interspecific Cuphea hybrids.

\begin{tabular}{|c|c|c|c|c|c|c|c|c|}
\hline \multirow{2}{*}{$\begin{array}{l}\text { Cross } \\
\text { no. }\end{array}$} & \multirow{2}{*}{$\begin{array}{l}\text { Hybrids, female and male } \\
\text { parents (accession no.) }\end{array}$} & \multirow{2}{*}{$\begin{array}{l}\text { Sample } \\
\text { size }\end{array}$} & \multicolumn{6}{|c|}{ Enzymes ${ }^{z}$} \\
\hline & & & 6-PGD & PGM & SKDH & PGI & DIA & $\mathrm{MDH}$ \\
\hline 1067 & $\begin{array}{l}\mathrm{F}_{1} \\
\text { C. lanceolata (A226) } \\
\text { C. viscosissima (A49) }\end{array}$ & $\begin{array}{r}122 \\
15 \\
22\end{array}$ & Yes & Yes & Yes & No & No & No \\
\hline 1069 & $\begin{array}{l}\mathrm{F}_{1} \\
\text { C. viscosissima (A49) } \\
\text { C. lutea }(\mathrm{A} 381)\end{array}$ & $\begin{array}{r}14 \\
22 \\
6\end{array}$ & Yes & Yes & No & Yes & No & No \\
\hline 1070 & $\begin{array}{l}\mathrm{F}_{1} \\
\text { C. ignea (A57) } \\
\text { C. angustifolia (A5) }\end{array}$ & $\begin{array}{l}5 \\
8 \\
4\end{array}$ & Yes & Yes & No & No & $--\cdot$ & No \\
\hline 1006 & $\begin{array}{l}\mathrm{F}_{1} \text {. } \\
\text { C. leptopoda }(\mathrm{A} 65) \\
\text { C. laminuligera }(\mathrm{A} 142)\end{array}$ & $\begin{array}{r}4 \\
16 \\
16\end{array}$ & Maternal & No & No & No & --- & Maternal \\
\hline 1014 & $\begin{array}{l}\mathrm{F}_{1} \text {. llavea (A69) } \\
\text { C. procumbens (A263) }\end{array}$ & $\begin{array}{r}3 \\
18 \\
10\end{array}$ & No & No & No & No & $\cdots$ & $\ldots$ \\
\hline
\end{tabular}

${ }^{2}$ Yes $=$ hybrids can be distinguished from parental species; No = hybrids indistinguishable from parental species; Maternal = hybrids same as maternal parent; --- = resolution too poor for analysis.

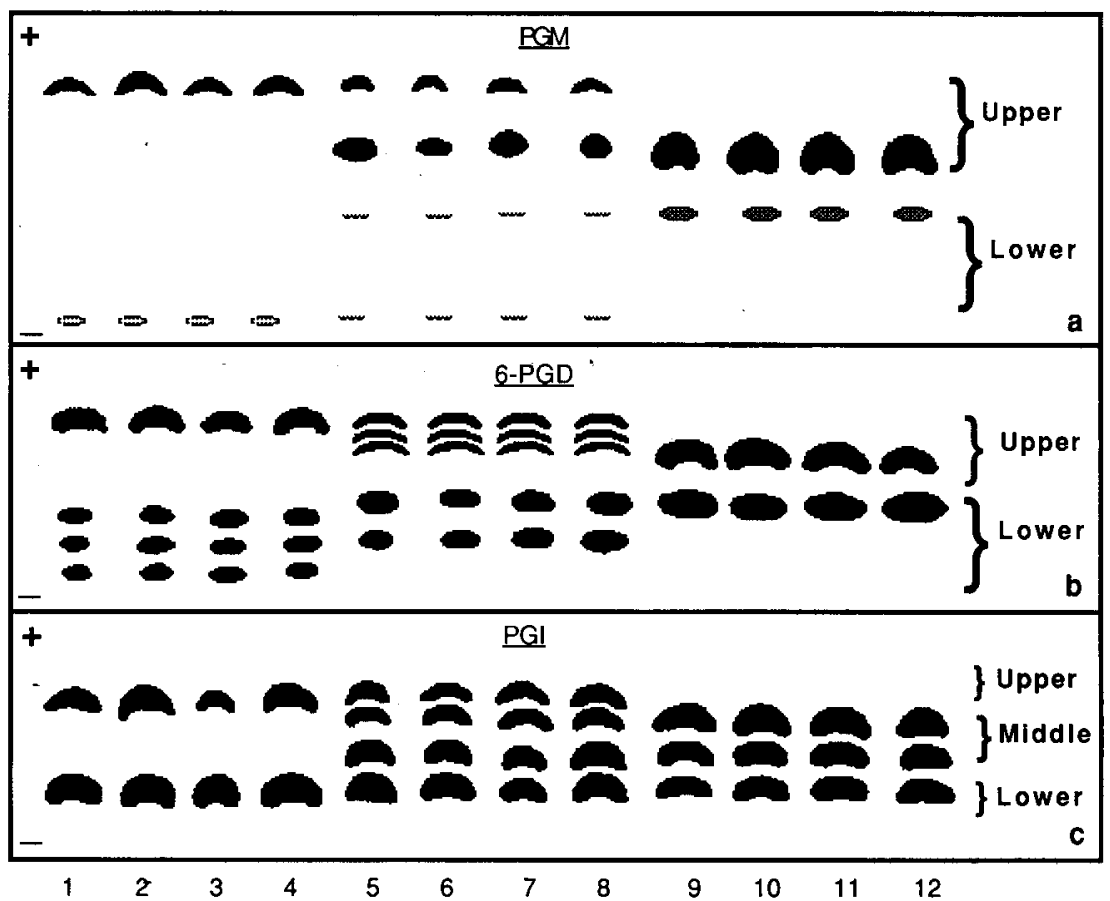

Fig. 1. Isozyme patterns of $C$. viscosissima (lanes 1-4), C. lutea (lanes 9-12), and the interspecific cross no. 1069 (lanes 5-8) for phosphoglucomutase (PGM); 6-phosphogluconic dehydrogenase (6$\mathrm{PGD}$ ) and phosphoglucose isomerase (PGI).

$(\mathrm{n}=10) \times C$. laminuligera $(\mathrm{n}=10)$, which was highly sterile, has had its fertility restored through chromosome doubling with colchicine (Ray et al., 1988, 1989). The $C$. ignea $\times C$. angustifolia cross is of special interest since it is the first interspecific hybrid between species of different taxonomic sections of the genus, Sect. Melvillia and Sect. Heterodon, respectively.

Availability of genetic markers for confirming hybridity is one of the primary needs of a hybridization program. Until recently, there have not been any genetic markers available for Cuphea species. Thompson (1989) reported on a single recessive gene, designated si for shortened internodes, that conditions a compact growth habit in plants within populations of $C$. leptopoda. Heritable isozyme variation has been characterized within three species: $C$. lanceolata (Knapp and Tagliani, 1989), C. laminuligera, and C. lutes (Krueger and Knapp, 1988).

Our objectives were to characterize the isozyme band patterns of parental species and to determine if these patterns could be used to identify various Cuphea interspecific hybrids.

The five interspecific Cuphea hybrids examined in this study (Table 1) were made at the U.S. Dept. of Agriculture Water Conservation Laboratory, Phoenix, Ariz., and by affiliated researchers using controlled pollinations. Records were kept of which parental accessions were used in the crosses but not of the original parental plants. Therefore, hybrid verification was based on a comparison of parental accessions and not of original parental plants. Putative hybrid plants were grown in the greenhouse along with a random sample of plants from both parental accessions. Seeds were planted in 2.4-liter pots containing Sunshine \#1 mix (Fisons, Vancouver, B.C.), watered daily, and fertilized weekly with $500 \mathrm{ml}$ of Growmore solution $\left(0.5 \mathrm{~g} \cdot\right.$ liter $^{-1}$; 20N-20P-20K plus micronutrients).

Isozyme analysis followed the general procedures of Cardy and Beversdorf (1984). Specific buffers and stain recipes were those used by Knapp and Tagliani (1989). After starch gel electrophoresis of leaf extracts, putative hybrid plants and parental accessions were scored for 6-phosphogluconic dehydrogenase (6-PGD; EC 1.1.1.43), phosphoglucomutase (PGM; EC 2.7.5.1), shikimate dehydrogenase (SKDH; EC 1.1.1.25), phosphoglucose isomerase (PGI; EC 5.3.1.9), diaphorase (DIA; EC 1.6.4.3), malate dehydrogenase (MDH; EC 1.1.1.37), aconitase (ACO; EC 4.2.1.3), and isocitrate dehydrogenase (IDH; EC 1.1.1.41). ACO and IDH bands were either too faint or too poorly resolved to use. After completion of electrophoresis, gel slices were fixed in a solution of 5 methanol : 5 water : 1 glacial acetic acid (by volume) and sealed in plastic bags with a heat-sealer.

Figures 1 through 3 illustrate four representative isozymes for plants from each accession plus four from $F_{1}$ plants from each cross. Pictures of the gels were made on a copy machine and the images were then transferred to a computer (Macintosh II) via an optical scanner (Microtek MSF 300C), edited with Superpaint software, and then printed on an Apple LaserWriter II.

Three of the interspecific hybrids, C. lanceolata $\times$ C. viscosissima, C. viscosissima $\times$ $C$. lutea, and $C$. ignea $\times C$. angustifolia, produced a clear hybrid isozyme band pattern in at least two enzyme systems (Table 1). The other two interspecific hybrids, $C$. llavea $\times C$. procumbens and C. leptopoda $\times$ $C$. laminuligera, showed no clear hybrid pattern in any enzyme system tested.

C. viscosissima $\times$ C. lutes. In the $C$. viscosissima $\times C$. lutea hybrid (cross no. 1069), three enzyme systems, PGM, 6-PGD, and PGI, showed a hybrid band pattern in the $F_{1}$ plants (Table 1). In the PGM enzyme system, upper bands showed an additive band pattern in the $\mathrm{F}_{1}$ plants with one band contributed from each parental accession (Fig. la). The lower PGM bands also showed a hybrid pattern (Fig. 1a), but were too faint, especially in the $F_{1}$ plants, to be routinely used for hybrid verification.

The upper bands of the 6-PGD enzyme system showed a hybrid dimeric band pattern in the $F_{1}$ plants (Fig. lb). The lower set of bands showed an additive band pattern in the $\mathrm{F}_{1}$ with different bands contributed by each parental accession. The genetic control of these bands is not readily apparent.

The PGI enzyme system (Fig. 1c) showed an additive, four-band pattern in the $F_{1}$ with the upper band contributed by the maternal plant, two middle bands contributed by the paternal plant, and the lowest band common to both parents. 


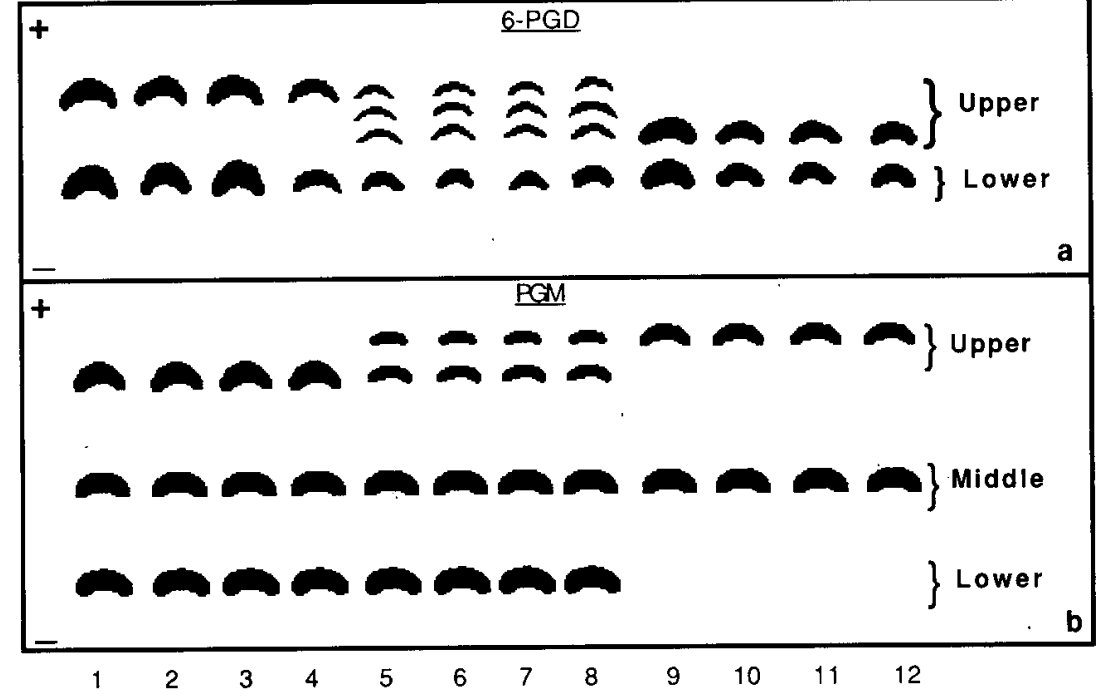

Fig. 2. Isozyme patterns of $C$. ignea (lanes 1-4), C. angustifolia (lanes 9-12), and the interspecific cross no. 1070 (lanes 5-8) for 6-phosphogluconic dehydrogenase (6-PGD) and phosphoglucomutase (PGM).

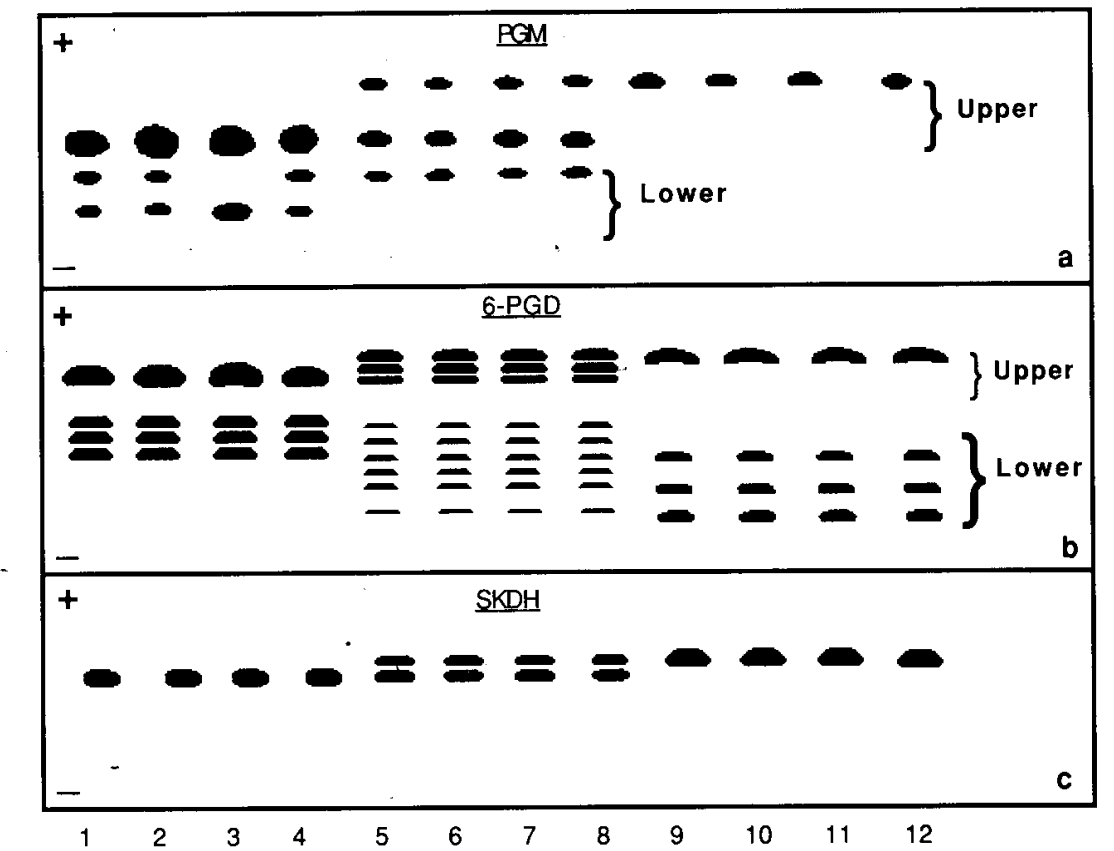

Fig. 3. Isozyme patterns of $C$. lanceolata (lanes 1-4), C. viscosissima (lanes 9-12), and the interspecific cross no. 1067 (lanes 5-8) for phosphoglucomutase (PGM), phosphogluconic dehydrogenase (6-PGD), and shikimate dehydrogenase (SKDH).

The inheritance of the isozyme bands that displayed a hybrid pattern cannot be tested in the $C$. viscosissima $\times C$. lutea cross because the $F_{1}$ plants were sterile. None of the other enzyme systems analyzed for this cross showed a hybrid band pattern in the $\mathrm{F}_{1}(\mathrm{Ta}-$ ble 1).

C. ignea $\times C$. angustifolia. In the $C$. ignea $\times C$. angustifolia cross (no. 1070), two enzyme systems, 6-PGD and PGM, produced a hybrid band pattern in the $\mathrm{F}_{1}$ plants (Table 1). The upper 6-PGD enzyme band contributed by each parent produced a hybrid dimeric pattern in the $F_{1}$ plants (Fig. 2a). There is a lower invariant band present in both parents, probably representing a second 6-PGD locus (Fig. 2a).
In the PGM enzyme system, the upper bands contributed by each parent produced a hybrid band pattern in the $F_{1}$ (Fig. 2b). The middle band was invariant and probably represents a second PGM locus. The lower PGM band is the same in the $F_{1}$ as in the maternal parent, with the paternal parent being null for this band (Fig. 2b). The lower band could be used to confirm hybridity only if the null band was contributed by the maternal parent.

The inheritance of the 6-PGD and PGM bands cannot be tested because the $C$. viscosissima $\times C$. lutea hybrid is sterile. None of the other enzyme systems tested showed a clear hybrid band pattern for this cross (Table 1).
C. lanceolata $\times$ C. viscosissima. For the C. lanceolata $\times$ C. viscosissima interspecific hybrid (cross no. 1067), three enzyme systems, PGM, 6-PGD, and SKDH, produced a hybrid band pattern in the $\mathrm{F}_{1}$ plants (Table 1). The upper PGM band contributed by each parent produced an additive monomeric hybrid band pattern in the $F_{1}$ (Fig. 3a). The lower band seen in the $F_{1}$ plants is contributed by $C$. lanceolata and probably represents a second PGM locus not present in C. viscosissima. This second locus appears to be heterozygous in lanes 1,2 , and 4 and homozygous for the slow form in lane 3 (Fig. $3 a)$. Since the parental plants used to create the hybrid were not known, it can only be inferred that the maternal parent was either homozygous for the fast band of the second locus or was heterozygous for the second locus and contributed the fast band to the hybrid plants.

The upper bands of 6-PGD showed a hybrid dimeric band pattern in the $F_{1}$ plants (Fig. 3b). The lower set of 6-PGD bands also showed a hybrid band pattern with three bands contributed by each parent producing a sixband pattern in the hybrid. This complex pattern possibly results from the interaction of two 6-PGD loci.

SKDH showed an additive, hybrid band pattern with single bands contributed by each parent probably being allelic (Fig. 3c). All other enzyme systems tested for the $C$. lanceolate $\times C$. viscosissima cross did not show hybrid band patterns in the $\mathrm{F}_{1}$ (Table 1). The $F_{1}$ plants are fertile and the inheritance of isozyme bands for several enzyme systems remain to be analyzed.

In the $C$. lanceolata $\times C$. viscosissima cross (no. 1067), a few putative hybrid plants were compared to the parental accessions for isozyme banding pattern. Once a hybrid band pattern was established, 14 of 122 putative hybrid plants were identified as selfs in three enzyme systems. A second cross involving the same species, C. lanceolata $\times C$. viscosissima (cross no. 1068) was then scored for hybridity and 18 of 39 putative hybrid plants were determined to be selfs. In both crosses, verification of hybridity based on morphological traits (data not shown) produced identical results to the isozyme analysis.

C. leptopoda $\times$ C. laminuligera. For the C. leptopoda $\times$ C. laminuligera interspecific hybrid (cross no. 1006), no clear hybrid band pattern emerged in any of the enzyme systems tested (Table 1). Two of the enzyme systems, MDH and 6-PGD, exhibited an unusual band pattern in which only maternal bands were present in the hybrid plants. Other enzyme systems either showed no difference between parental accessions or had so much variation within each accession that the hybrid plants could not be clearly differentiated from either parent.

C. llavea $\times$ C. procumbens. The $C$. llavea $\times C$. procumbens hybrid (cross no. 1014) produced no clear hybrid band pattern for any of the enzyme systems tested (Table 1). For some enzyme systems, the parental band patterns were too similar to be distinguished from each other. In other enzyme systems, 
the band pattern of one parent was similar to the band pattern of the second parent but included additional bands. In this instance, the parent having the additional bands could not be distinguished from the hybrid.

For all five interspecific hybrids analyzed, the hybrid plants were compared to a random, sample of plants from the parental accessions and not the specific parental plants used in making the crosses because the latter were no longer available, This made verification of hybridity often difficult, particularly in cases where isozyme variability was present within the parental accessions. Variability within parental accessions obscured distinct differences between species. In the three interspecific hybrids confirmed by isozyme analysis, four of the five accessions involved (A49, A381, A57, A5) showed little or no within-accession variability for any of the enzyme systems assayed. Since parental accessions were genetically uniform, differences between species were readily apparent and the $F_{1}$ band pattern was distinguishable from that of both parents. In contrast, in the two interspecific hybrids not confirmed by isozyme analysis, three of the four parental accessions (A65, A142, and A69) had substantial isozyme variability for several enzyme systems. Not surprisingly, some of the species that displayed isozyme uniformity $(C$. lutea and $C$. viscosissima) are predominately self-pollinating while some of those that showed considerable variability $(C$. llavea, $C$. leptopoda, and $C$. laminuligera) are predominately cross-pollinating (Graham, 1988).

These five interspecific hybrid combinations have previously been verified through other analyses. C. llavea $\times C$. procumbent, C. leptopoda $\times C$. laminuligera, and C. ignea $\times C$. angustifolia have been confirmed both morphologically and cytologically (Ray et al., 1988; Thompson et al., 1989). F plants of $C$. viscosissima $\times C$. lutea and $C$. lanceo- lata $\times$ C. viscosissima have flower traits (color, shape) that are intermediate to their parents. However, isozyme analysis has several advantages over morphological or cytological analyses that make the development of isozyme markers extremely useful.

First, the isozyme analysis is usually precise, whereas there often is a degree of uncertainty in the morphological analysis. With isozyme analysis, if enzyme bands from both parents are present in the $\mathrm{F}_{1}$, then the plant must be a hybrid. Morphological traits are typically intermediate between the parental traits and are not always readily distinguishable from one or both parents. In the C.lanceolata $\times C$. viscosissima cross, although the hybrids have flower traits intermediate to the parental accessions, these traits are much closer to the maternal parent traits, which often makes the analysis uncertain.

Second, isozyme analysis can be performed faster than other types. In Cuphea, the isozyme analysis can be performed on 3to 5-day-old seedling tissue. A morphological analysis based on flower traits or a cytological analysis based on meiotic stages could not be done for at least 6 to 8 weeks. Also, isozyme analysis can be used to screen up to 100 or more plants per day, whereas a cytological analysis would be limited to $\approx 10$.

Third, if the interspecific hybrid is fertile, as in the case of $C$. lanceolata $\times C$. viscosissima, isozyme analysis can be extremely useful for performing many additional studies. When the $\mathrm{F}_{2}$ plants show segregation of isozyme bands, then inheritance and linkage information can be obtained easily. Once Mendelian inheritance is established, then the gene markers can be used for a variety of purposes, including taxonomic studies, monitoring introgression of traits, assaying genetic variability within and between species, determining outcrossing rates, and mapping quantitative traits.
Literature Cited

Cardy, B.J. and W.D. Beversdorf. 1984. A procedure for the starch gel electrophoretic detection of isozymes of soybean (Glycine max [L. ] Merr.). Dept. Crop Sci. Tech. Bul. 119/8401. Univ. of Guelph, Guelph, Ont.

Gathman, A.C. and D.T. Ray. 1987. Meiotic analysis of 14 Cuphea species and two interspecific hybrids. J. Hered. 78:315-318.

Graham, S.A. 1988. Revision of Cuphea section Heterodon (Lythraceae). Systematic Bot. Monogr. 20:1-168.

Hirsinger, F. 1985. Agronomic potential and seed composition of cuphea, an annual crop for lauric and capric seed oils. J. Amer.Oil Chem. Soc 62:76-80.

Hirsinger, F. and P.F. Knowles. 1984. Morphological and agronomic descriptions of selected Cuphea germplasm. Econ. Bot. 38:439-451.

Knapp, S.J. and L.A. Tagliani. 1989. Genetics of allozyme variation in Cuphea lanceolata Ait. Genome 32:57-63.

Krueger, S.K. and S.J. Knapp. 1988. Isozyme variation in Cuphea laminuligera and Cuphea lutea. HortScience 23:768. (Abstr.)

Ray, D.T., A.C. Gathman, and A.E. Thompson. 1989. Cytogenetic analysis of interspecific hybrids in Cuphea. J. Hered. 80:329-332.

Ray, D.T., A.E. Thompson, and A.C. Gathman. 1988. Interspecific hybridization in Cuphea. HortScience 23:751-753.

Thompson, A.E. 1984. Cuphea - a potential new crop. HortScience 19:352-354.

Thompson, A.E. 1985. New native crops for the arid Southwest. Econ. Bot. 39:436-453.

Thompson, A.E. 1989. Nature and inheritance of compact plant habit in Cuphea leptopoda Hemsley. HortScience 24:368-370.

Thompson, A.E. and R. Kleiman. 1988. Effect of seed maturity on seed oil, fatty acid and crude protein content of eight Cuphea species. J. Amer. Oil Chem. Soc 65:139-146.

Thompson, A.E., D.T. Ray, and M.S. Rob. 1987. Evaluation of Cupheaprocumbens $\times$ C. llavea hybrids as new floral and bedding plants. HortScience 22:1142-1143. (Abstr.) 